\title{
Large Signal Modulation and Distortion in a Microwave Phase Shifter Based on Slow Light in a Semiconductor Waveguide
}

Chen, Yaohui; Öhman, Filip; Mørk, Jesper

Published in:

CLEO/QELS 2006 Technical Digest CD-Rom

Link to article, DOI:

10.1109/CLEO.2006.4627829

Publication date:

2006

Document Version

Publisher's PDF, also known as Version of record

Link back to DTU Orbit

Citation (APA):

Chen, Y., Öhman, F., \& Mørk, J. (2006). Large Signal Modulation and Distortion in a Microwave Phase Shifter Based on Slow Light in a Semiconductor Waveguide. In CLEO/QELS 2006 Technical Digest CD-Rom (pp. 1-2). IEEE. https://doi.org/10.1109/CLEO.2006.4627829

\section{General rights}

Copyright and moral rights for the publications made accessible in the public portal are retained by the authors and/or other copyright owners and it is a condition of accessing publications that users recognise and abide by the legal requirements associated with these rights.

- Users may download and print one copy of any publication from the public portal for the purpose of private study or research.

- You may not further distribute the material or use it for any profit-making activity or commercial gain

- You may freely distribute the URL identifying the publication in the public portal 


\title{
Large Signal Modulation and Distortion in a Microwave Phase Shifter Based on Slow Light in a Semiconductor Waveguide
}

\author{
Yaohui Chen, Filip Öhman, and Jesper Mørk \\ COM.DTU Department of Communications, Optics \& Materials, NanoDTU, Technical University of Denmark \\ Build.345v, DK-2800 Kgs. Lyngby, Denmark, jm@com.dtu.dk
}

\begin{abstract}
We model slow-light propagation in an active semiconductor waveguide in the large modulation depth regime. Distortion from higher harmonics is countered by filtering and the regenerating properties of the device further increase the modulation depth.
\end{abstract}

(C) 2005 Optical Society of America

OCIS codes: (230.4320) Nonlinear optical devices, (070.6020) Signal processing

\section{Introduction}

It has been experimentally demonstrated that slow light propagation can be achieved in active semiconductor waveguides [1,2]. The physical phenomenon responsible for the effect is denoted coherent population oscillations and can be interpreted as a four-wave mixing effect [2,3] or alternatively as due to dynamical absorption saturation [2]. Due to the excitation of oscillations in the carrier density of the device the magnitude of the effect depends on the carrier lifetime and is restricted by a delay-bandwidth product. This points to narrow-bandwidth applications, such as the phase-shifting of a microwave signal e.g. for optical feeding of phased-array antennas or processing of optical clock signals. While measurements and analysis so-far were carried out in the small-signal regime [2,3], we here analyze the consequences for the signal quality when operating in the regime relevant to the applications where the modulation depth is close to $100 \%$.

\section{Model}

Based on the analytical model of [2] and a detailed model for carrier dynamics [4] we numerically investigate a strong intensity modulated optical signal passing through a reverse voltage controlled electro-absorption modulator (EAM). The numerical EAM model [4] is based on a microscopic model of the semiconductor carrier density dynamics, considering carrier density depletion, carrier heating $(\mathrm{CH})$ and spectral-hole burning (SHB). The EAM has typical parameters: $0.18 \mathrm{pJ}$ saturation energy, 20ps carrier lifetime and small signal absorption $31.3 \mathrm{~dB}$ at $2 \mathrm{~V}$ reverse bias.

\section{Results}

As shown in Fig 1(a), an input optical signal at $15 \mathrm{GHz}$ with $100 \%$ modulation depth is strongly distorted at the output. A large phase shift is achieved at the rising edge of the signal, whereas zero phase shift is obtained at zero optical intensity. In order to reduce the distortion we use a low-pass filter (6-order Bessel filter with $\mathrm{f}_{3 \mathrm{~dB}}=15 \mathrm{GHz}$ ) to reshape the signal waveform, which also implies a change in the modulation depth. The EAM actually increases the modulation depth at the output of the waveguide due to the regenerating property of a saturable absorber [5]. The filtering also models the optical-to-electrical conversion taking place in a photodiode at the output. The resulting phase can be estimated from the $1^{\text {st }}$ harmonic of the spectrum and its voltage dependence is shown in Fig. 2(a).
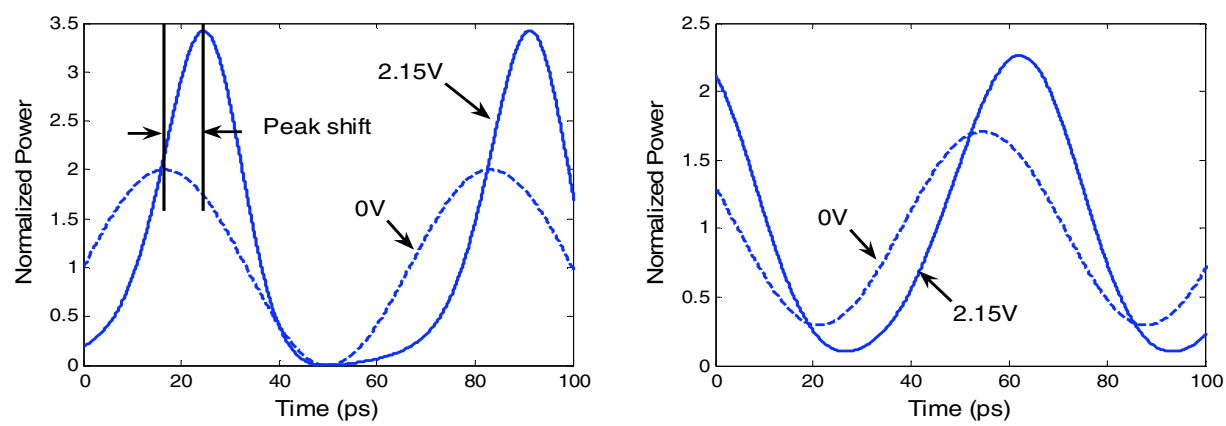

Fig. 1. Temporal variation of power (normalized by mean value) at the output of the EAM (a) without and (b) with a filter after the EAM at transparency $(0 \mathrm{~V})$ and at a reverse bias $(2.15 \mathrm{~V})$. The input power was $25 \mathrm{~mW}$. 


\section{CMN2.pdf}

As demonstrated in Fig. 2(a), large signal modulation (100\% modulation depth) introduces a small deviation between the numerical and the analytical result when the 1st harmonic is used to estimate the filtered output. However, the analytical results still provide a good approximation for the entire range of voltages. In order to estimate the effect of the higher harmonics, the phase shift corresponding to the time delay of the intensity peak is also included in Fig. 2(a). The difference between the peak shift (dashed line) and the $1^{\text {st }}$ harmonic (red line) provides an estimate of the reduction of phase shift resulting from the restoration of the signal by the filter. In Fig. 2(b), a further comparison between the analytical and large signal results shows that while the deviation increases with modulation depth it remains small in absolute terms. The deviation for small modulation depth is attributed to $\mathrm{CH}$ and SHB effects included in the simulation, which are neglected in the analytical model.
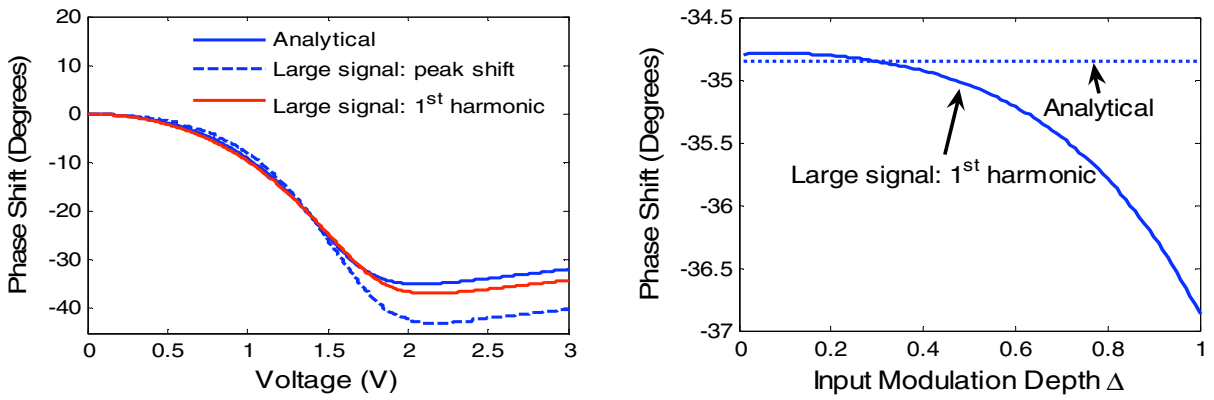

Fig. 2.Phase shift upon propagation in semiconductor waveguide. (a) Comparison of analytical result and large signal simulation for varying reverse bias for $100 \%$ modulation depth. (b) Comparison of analytical results with large signal simulation at $2.15 \mathrm{~V}$ for different modulation depths. The numerical phase is deduced from the Fourier spectrum (" $1 \mathrm{st}$ harmonic") as well as from the phase shift obtained at the peak of the temporal signal in Fig.1.

The byproduct of large-signal modulation is the introduction of high order harmonics, as quantified by the second-harmonic suppression ratio (SHSR) shown in Fig.3(a). The SHSR increases rapidly with input modulation depth but can to some degree be countered by filtering. The increase in output modulation depth resulting from the regenerating property of the saturable absorber [5] is seen in Fig. 3 (b). This demonstrates that even including the filtering it is possible to keep, or even improve, the modulation depth at the output of the device.
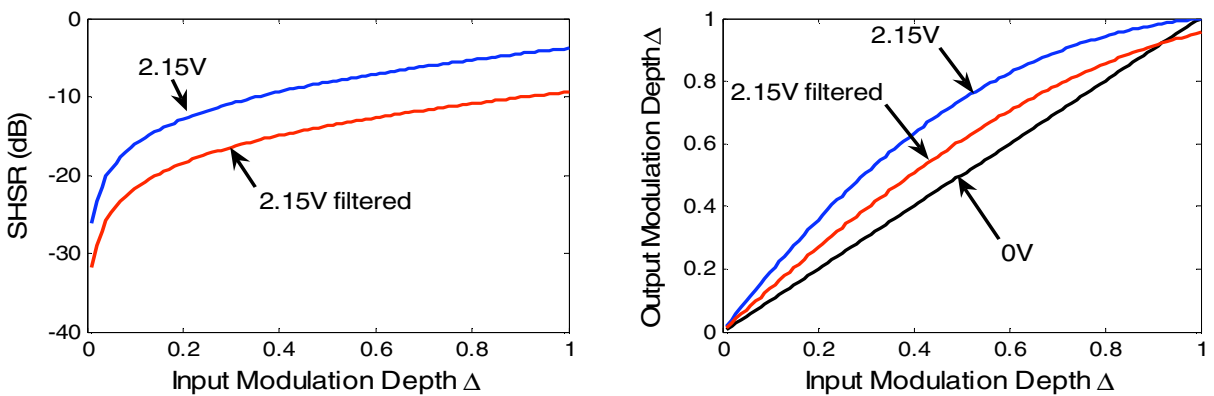

Fig. 3. Dependence of (a) Second-harmonic suppression ratio (SHSR) and (b) output modulation depth on the input modulation depth. Results are shown both before and after low-pass filtering at the output of the waveguide.

\section{Conclusions}

The simulations in this work demonstrate that the application of phase delay based on slow light in an active semiconductor waveguide is feasible even in a large signal modulation case. The distortions to the signal introduced by the nonlinearities of the saturable absorber can be countered by appropriate filtering without reduction of the phase delay. Furthermore, a small signal analytical model is shown to also describe the large signal modulation case to a good approximation.

\section{References}

[1] P. Palinginis et al., "Ultra-slow light $(<200 \mathrm{~m} / \mathrm{s})$ in a semiconductor nanostructure", Proc. OFC, Post deadline paper CPDB6, USA, May 2005.

[2] J. Mørk et al., "Slow light in a semiconductor waveguide at gigahertz frequencies," Opt. Express 13, 8136-8145 (2005).

[3] A. Uskov et al., "Slow and superluminal light in semiconductor optical amplifiers", Electronics Letters, 41, 922-924 (2005).

[4] A. Mecozzi et al., "Saturation effects in nondegenerate four-wave mixing between short optical pulses in semiconductor laser amplifier", IEEE J. Select. Topics Quantum Electron., 1190-1207 (1997).

[5] F. Öhman et al., "Noise and regeneration in semiconductor waveguides with saturable gain and absorption" IEEE J. Quantum Electron. 40, 245-255 (2004). 